\title{
Lightweight Grid Shell Pavilion - Design, Manufacture and Erection of Full Scale Grid Shell Prototypes
}

\author{
Aleš Vaněk \\ FCE CTU Prague, Department of architecture, Prague, Czech Republic \\ e-mail: vanek.alesvanek@gmail.com
}

\begin{abstract}
The main goal of author's research is to design and construct grid shell structures, which are subsequently realized as experimental structures in full scale. These structures should make the place suitable for various events and also a friendly, pleasant, relaxing and free time space. By thinking about how such structure should look like and what materials and structure types are suitable, there were many kinds of lightweight structures considered.

The most logical solution is to create a grid shell structure combining with a single layer membrane that would fulfill all aspects of elegant remarkable lightweight structure using some original details and workflow advancements. These grid shell projects should demonstrate another possibility to build and think about unconventional structures and provoke a deeper interest in these unique structures. The goal of this project was to create a feasible design of a grid shell structure and to build up the structures while being capable to understand the core of such an interesting phenomenon.
\end{abstract}

Key words: grid shell, structure, lightweight, pavilion, experiment, full scale

\section{Introduction}

The goal is to dulcify an exposed place to create a cozy space for pleasant relaxation. This place could have also the function of background for various events and should fulfill a function of an interesting signs. The design is about creating a partial cover structure, which would be able to make an area more pleasant. In term of lightweight structures we may first consider a single-layer tensile membrane, but there are another solutions possible, for example covered grid shell structure. Single-layer tensile membrane needs a primary structure system. In most cases, the system would require steel and cable components, which would not have been suitable because of visual impact of these components and less space providing. A grid shell does not need the above mentioned. It is a shell structure which stands clearly and clean, may in combination with a translucent membrane cover. The goal is to give an impression of lightness and elegance, aesthetics and originality. 


\section{Forerunners of grid shells}

There are introduced two main examples of grid shell evolution. A yurt, which was the traditional dwelling in the middle Asia since approx. 3000 years ago, as a predecessor could be considered a Tee-Pee structure. In case of yurt the grid is curved in one direction. " $A$ traditional yurt (from the Turkics or Mongolian) is a portable, round tent covered with skins orfelt and used as a dwelling by nomads in the steppes of Central Asia. The structure comprises an angled assembly or latticework of pieces of wood or bamboo for walls, a door frame, ribs (poles, rafters), and a wheel (crown, compression ring) possibly steam-bent." [1]

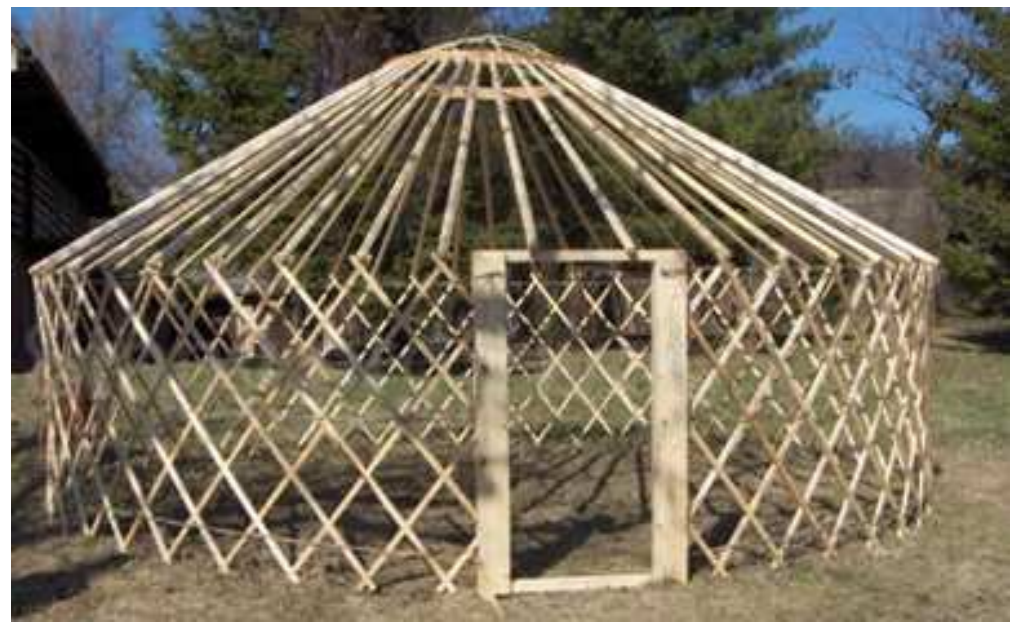

Figure 1: Mongolian Yurt - structural solution

\section{Advantages (and disadvantages) for using grid shells}

Advantages of using Grid shells in architecture may include: sustainable use of material such as timber, self forming process of the complex curved geometry during erection from an initially flat configuration, recyclable solution. These attributes makes grid shells economic both in minimal use of material and manufacturing costs, as such they may be considered sustainable. On the other side, the necessity of well done form-finding, the dependence on particular material properties and complex procedures during the erection and finally their low stiffness have kept grid shells in a niche compared to other modern shell structures.

\section{Form finding techniques}

Creating lightweight architecture, there is always the need of cooperation with many experts and specialists, architects, engineers, craftsmen etc., in the whole process from designing point to realization. In order to be able to create meaningful and reasonable concepts, here is no better way to start a lightweight structure design than using a physical model. In case of tensile membrane structures we are able to feel the tension from a stocking model and decide for the best solution - a convenient concept for further analysis. Computer tools may be less 
in the first step of the design, because they could form find many different shapes, which are not feasible in a next step of the design procedure. This is similar when designing grid shells. Holding a sheet of plastic grid, one may observe an infinite number of double curved shapes which are formed from one and the same grid. However, not every shape is easy or even possible to be built. It is essential to test many materials and techniques to be able to select the best grid material for building physical model.

Physically based options of form finding are suitable to find the form of a grid shell at model scale. For the full scale structure we need to consider real material properties, which have an influence on final shape and structural performance. These changes in scale can be significant especially in case of small form finding models. In general the larger the mode scale the better the relation between model and full scale structure. For initial design stages small scale models may be sufficient. However, it is necessary to make larger scale models and prototypes to test the structure and its detail.

\section{Grid Shell Case Study - Multihall, Mannheim}

An iconic grid shell structure, made for the Federal Garden Exhibition in Mannheim, which was brought on the light in 1975. An unique modeling system, which exactly describes final designed shape. In reality it is a huge structure with several saddle-shaped areas and one valley. For the grid the dimensions of $0,5 \times 0,5 \mathrm{~m}$ were used, because it allows a convenient walking on grid even on the roof skin. However, by working on the structure, mountaineers use securing cables, because of danger of slipping down when it is wet.

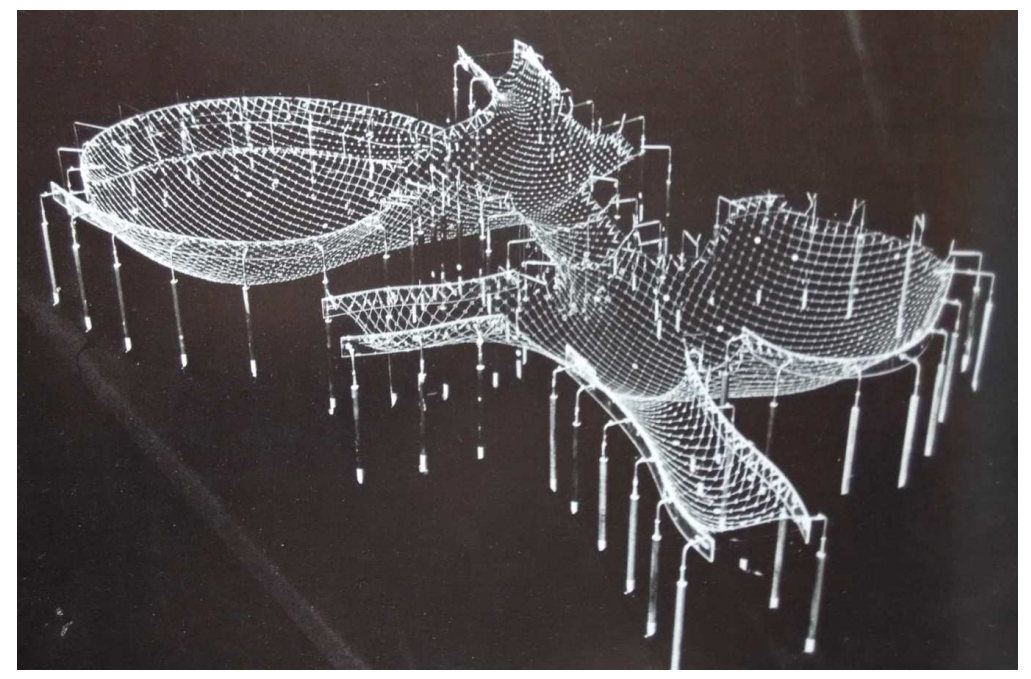

Figure 2: Suspended net model of the Multihall in Mannheim 


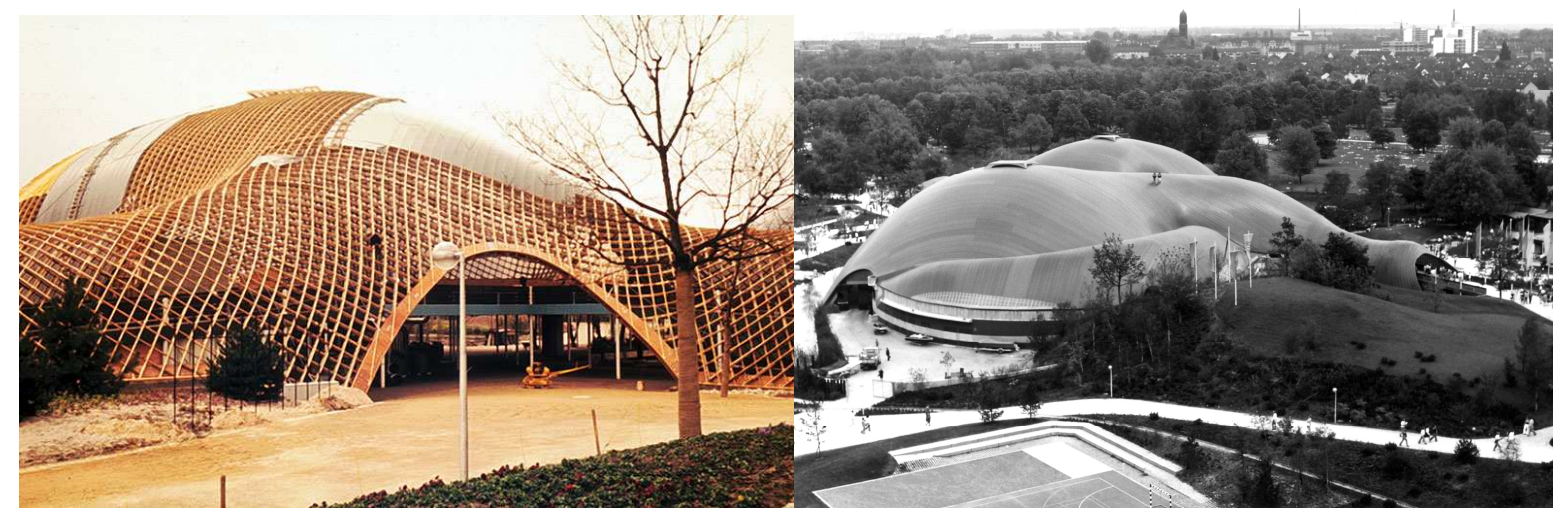

Figure 3 and 4: Realization of Multihall in Mannheim

\section{Experimental covering of a pool}

Structural experiment as a prototype structure for envisaged realization. Grid shell workshop took the place under authors organization and supervision of Arch. Dipl.-Ing. Jürgen Hennicke, who gave all necessary advices and brought a higher level to the workshop. His hand made hanging chain was used to find the designed form. Coming out from previously made physical model, which has been used for idea of intended shape, another model was made using the hanging chain method in scale 1:30. This model was subsequently measured and transferred to a real grid. The grid of total surface area $65,1 \mathrm{~m}^{2}$ made of smooth planed timber spruce laths $22 \times 46 \times 3000 \mathrm{~mm}$, axial dimensions of squares $500 \times 500 \mathrm{~mm}$, each connection using socket screw $\varnothing 5 \mathrm{~mm}+2 \mathrm{x}$ washer + nut. After cutting out all overlaps the final grid was "folded" (pulled from two opposite sides in direction to the middle and fixed with perpendicular laths to reach minimal surface for better shifting), taken to the building side and erected.

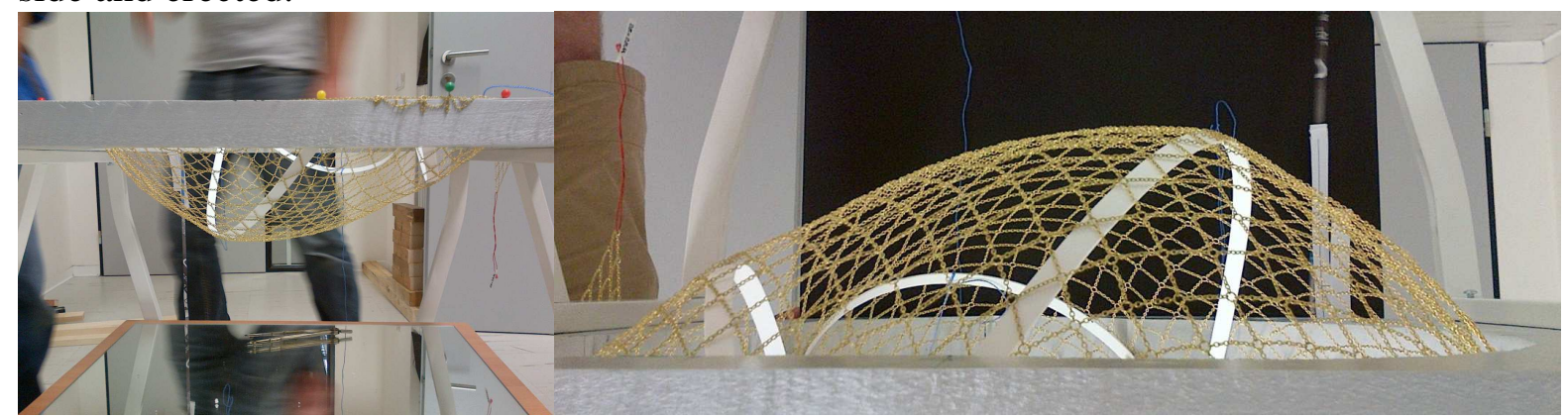

Figure 5 and 6: Hanging/inverted chain physical model 


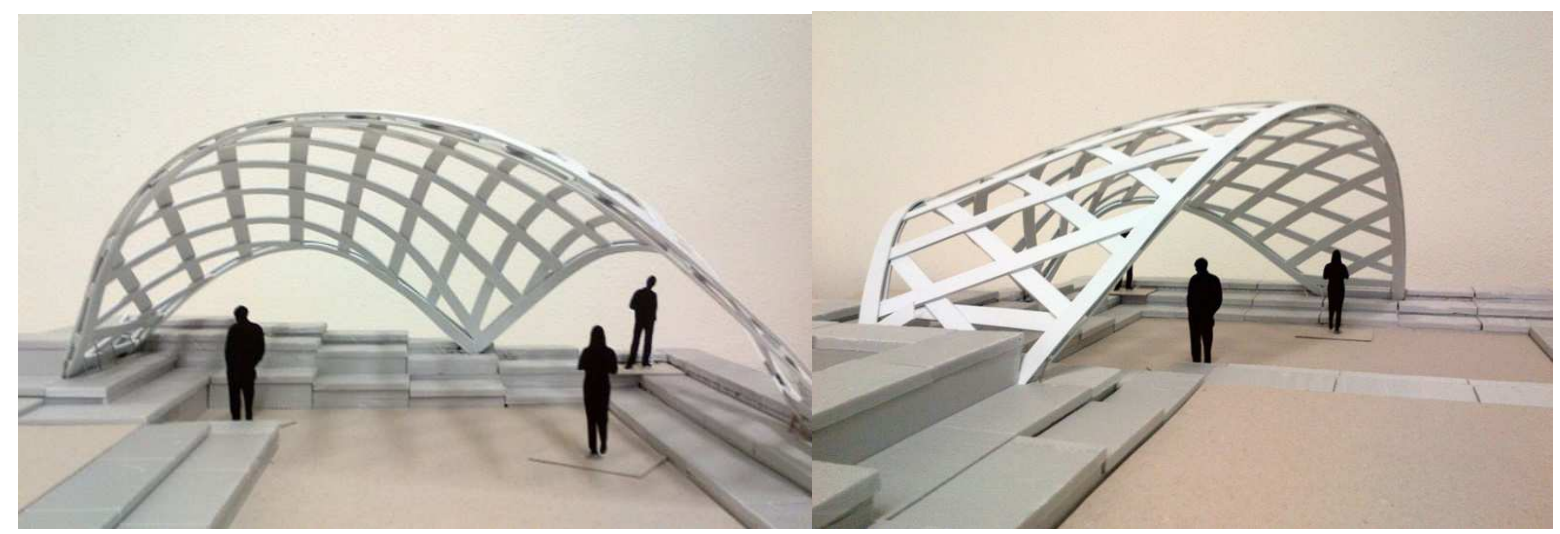

Figure 7 and 8: Final shape physical model

One of the last and most exciting parts of whole procedure is the Grid shell erection process. This process is time consuming, because it is necessary to erect the whole grid at one moment in gradual steps and keep it in the final position until final reinforcements are done.

At first the completed timber grid was folded (squeezed), reinforced with perpendicularly laths fastened using zip ties for better manipulation of the grid and to get the grid safe without breakages to the starting position. After that the Grid was settled to the position in the pool and supported by horizontally fixed ladders.

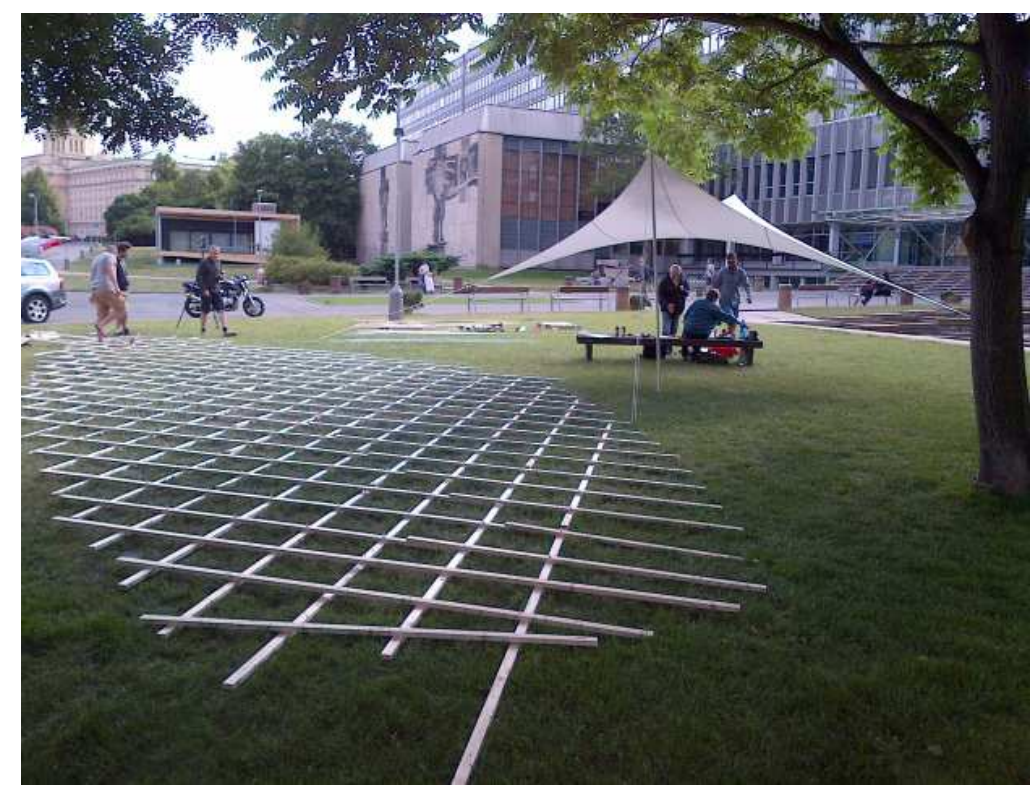

Figure 9: Flat grid mesh before the final adjustments

After releasing, the grid was slowly spread out, which caused non symmetric force distributions (one part was situated on the flat grass surface and the other one was slacking inside the pool), because just three horizontal ladders were installed. The ladders were used afterwards also as vertical supporting elements. This proved to be an in practical solution, because the grid in higher position which is ,pierced“with the ladder is not movable. As a 
result it is not possible to change the ground plan position easily. Another problem is a small contact surface with the supporting element which causes more breakages as compared to using flat-head elements. Doing some more attempts the whole grid was brought to the starting position and continued again next to the pool on the green grass surface.

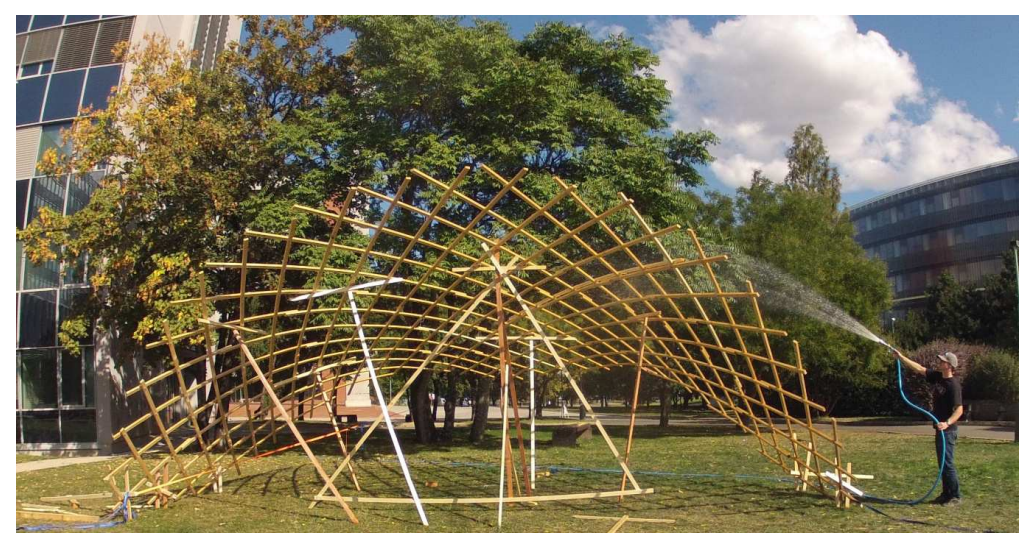

Figure 10: Erection procedure - final shape supported and anchored

The other important thing is to spread out resp. shrink the grid into the right rhombic angle to prevent further necessity of changing it. Later on this is very difficult due to the shape, which is already bent. This is a very important step, also the most demanding, time consuming and heavy on costs by using proper scaffolding, which has to be able to be dismantled after the whole structure is erected and fixed. When lifting up the whole grid during the first workshop many mistakes were made, which would not be even predictable without doing this experiment. It was really helpful to understand how the grid structure acts, especially in case we change one point of the grid, the whole grid changes.

In this experimental case there was the erection done by prepared long laths with shorter laths perpendicularly drilled to the end which creates „T" shape. With such bars the whole grid was erected and at the same time two pieces of fastened straps secured horizontally. When the final ground floor plan was settled, lines sitting on the ground were anchored to the ground using rest pieces of timber.

After lifting up the grid to a sufficient height, tightening all screws and anchoring timber parts in contact with the ground, the periphery fixation needs to be done in the whole perimeter to fix the laths position so that they have no more chance to deviate from the given position. 


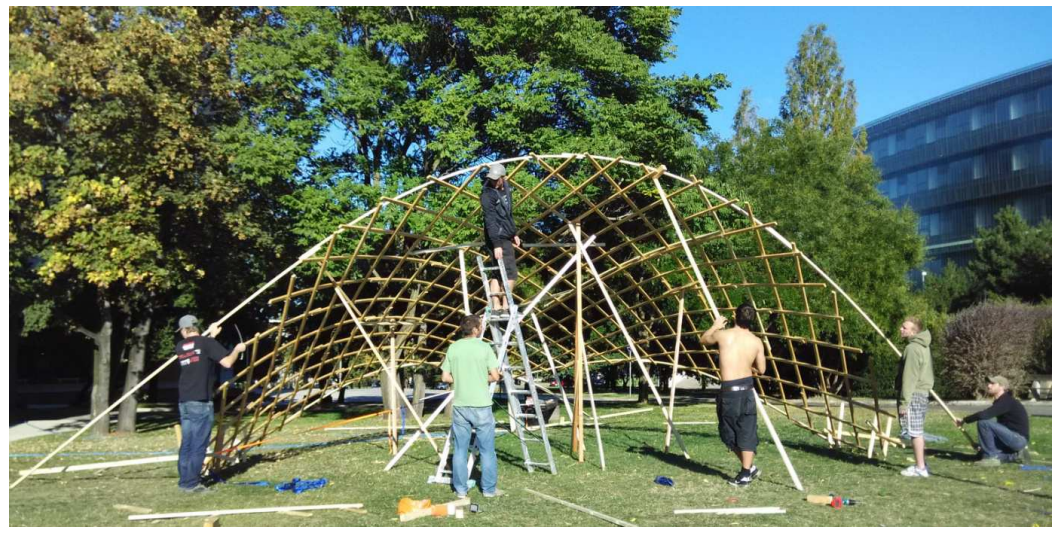

Figure 11: Final shape perimeter tightening

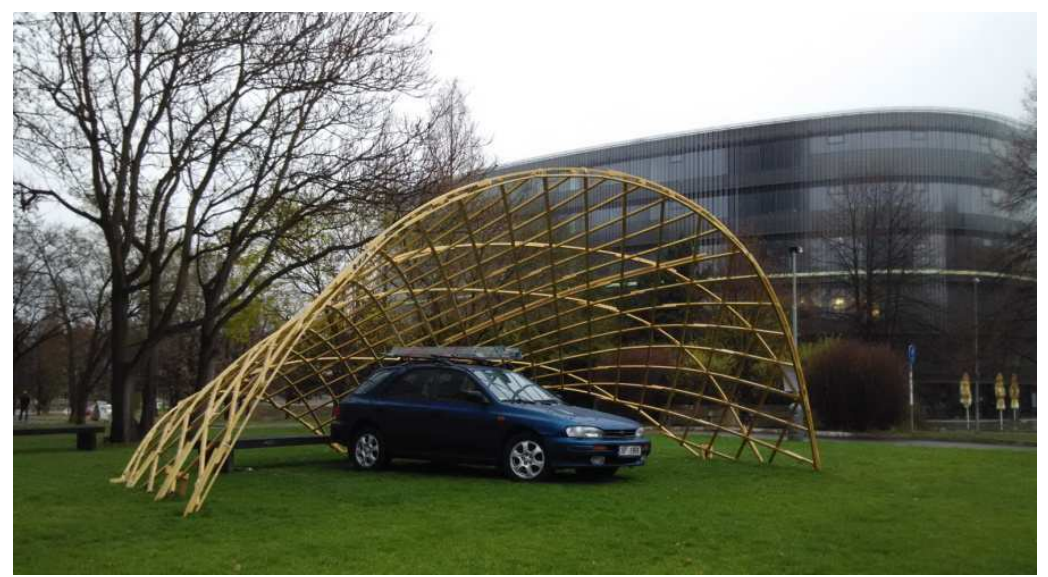

Figure 12: Final shape of the pavilion

When final shape is reached and the perimeter fixed, additional timber laths on the top from along the whole perimeter are necessary to be attached. In the case of the covering there were used additional three lines, which would be not sufficient for a real long-term structure. For peripheral stiffen a second layer from the bottom may help a lot, because these structural parts are most strained.

This construction step helps a lot to represent the grid shell with highlighted perimeter lines and finally defines finished structure.

\section{Roof for a temporary theatre for mentally handicapped people}

All previously reached experiences were utilized in the next realization of a sustainable temporary project for covering a theatre at a traditional summer fair. The mission was to cover an area of approximately $370 \mathrm{~m}^{2}$. The primary structure of walls was made from 115 hay bundles, each of dimensions 900x1200x2400 mm. Altogether for the larch tree timber grid shell roof of 3 tons weight 550 laths of $3 \mathrm{~m}$ length were used. For the connections details 
1600 screws and nuts, 3200 washers were used. This structure was, except for its expanse, not different from previous mentioned structures and used connections.

The pine tree timber as a good choice for this purpose, in comparison to spruce timber has better characteristics and caused not so many breakages. The big advantage by the realization was the possibility to use heavy tools like manipulators and crane. The whole roof was dismantled and erected on the ground and reinforced transversely. The edge was measured and marked out, after that all shifted with the crane sideward to bring it back when the walls from hay bundles were finished. The complete roof area was covered by a simple waterproof canvas, black from inside because of the theatre requirements. Horizontal forces secured by tensioned steel cables.

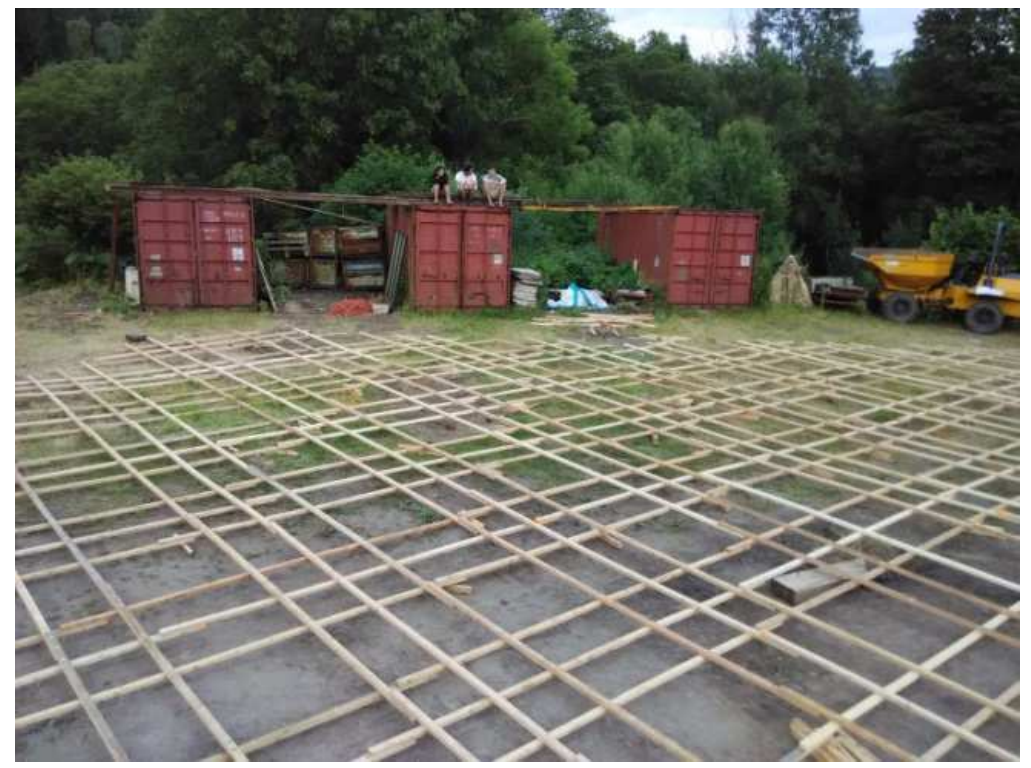

Figure 13: - Flat grid mesh before erection

The final grid was made from not planed larch timber laths, which weren't precisely prepared due to the drilled holes they didn't match together and new holes were drilled on site. This made the realization a bit slower. There were about 8-10 people working 6 full days to realize the final structure. 


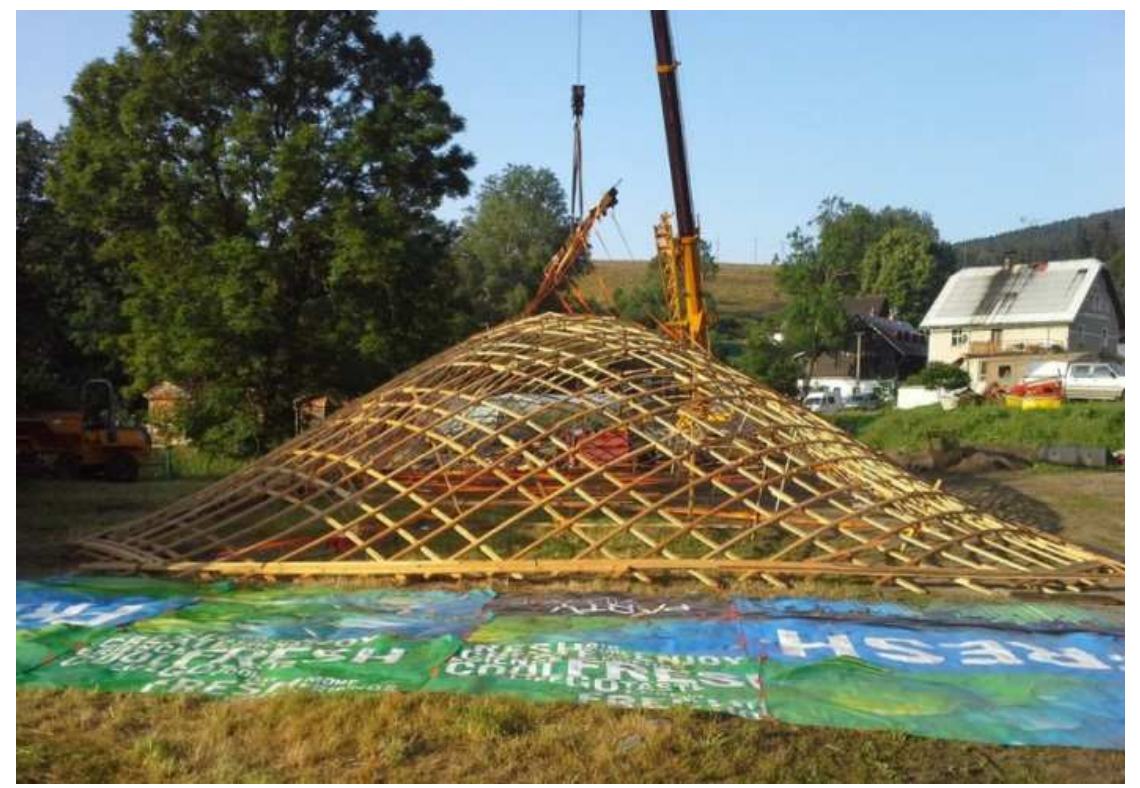

Figure 14: Erected Grid mesh, peripheral fixation

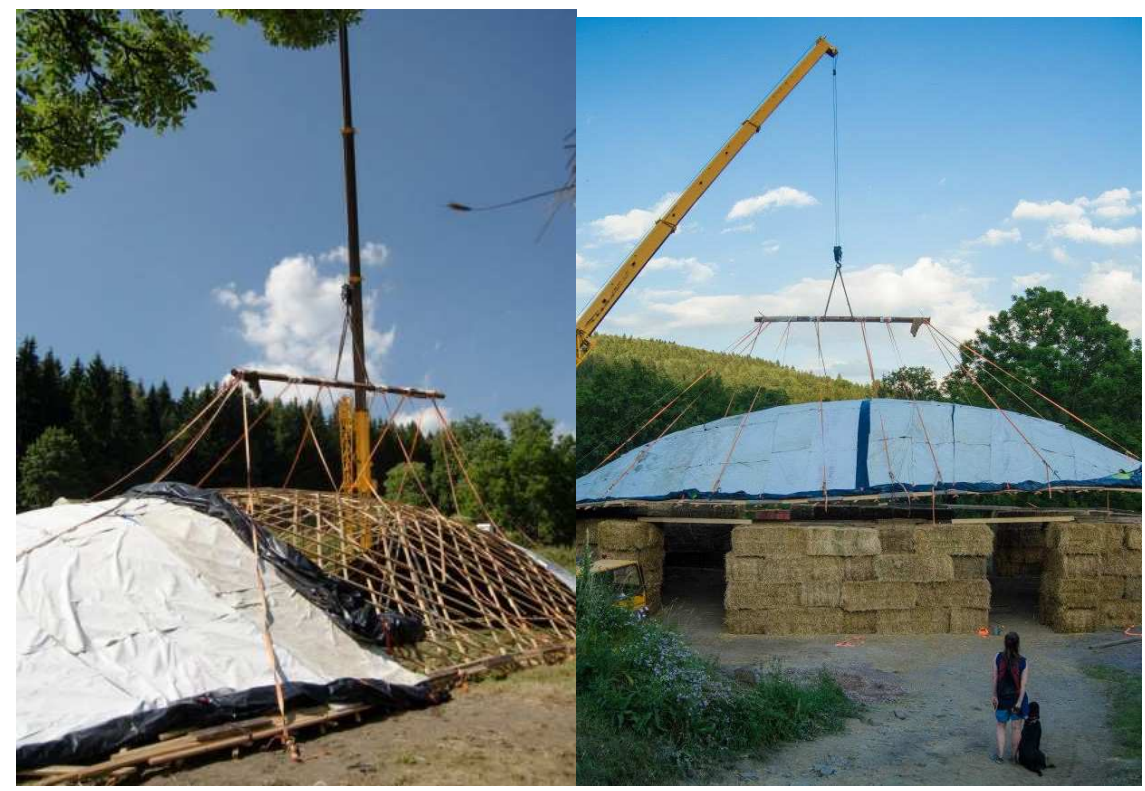

Figure 15: Roof covering with canvas Figure 16: Finished roof placing

The grid was first made in the grid density $1 \times 1 \mathrm{~m}$, in the second step additional laths were added to reinforce the grid in a half of the area. Important to notify that this roofing was build just with a feeling and predicting the structural behavior. Looking inside to the physical model and to the realized structure we are able to feel the lightness across a big span which makes grid shells irreplaceable in their originality and simplicity. 


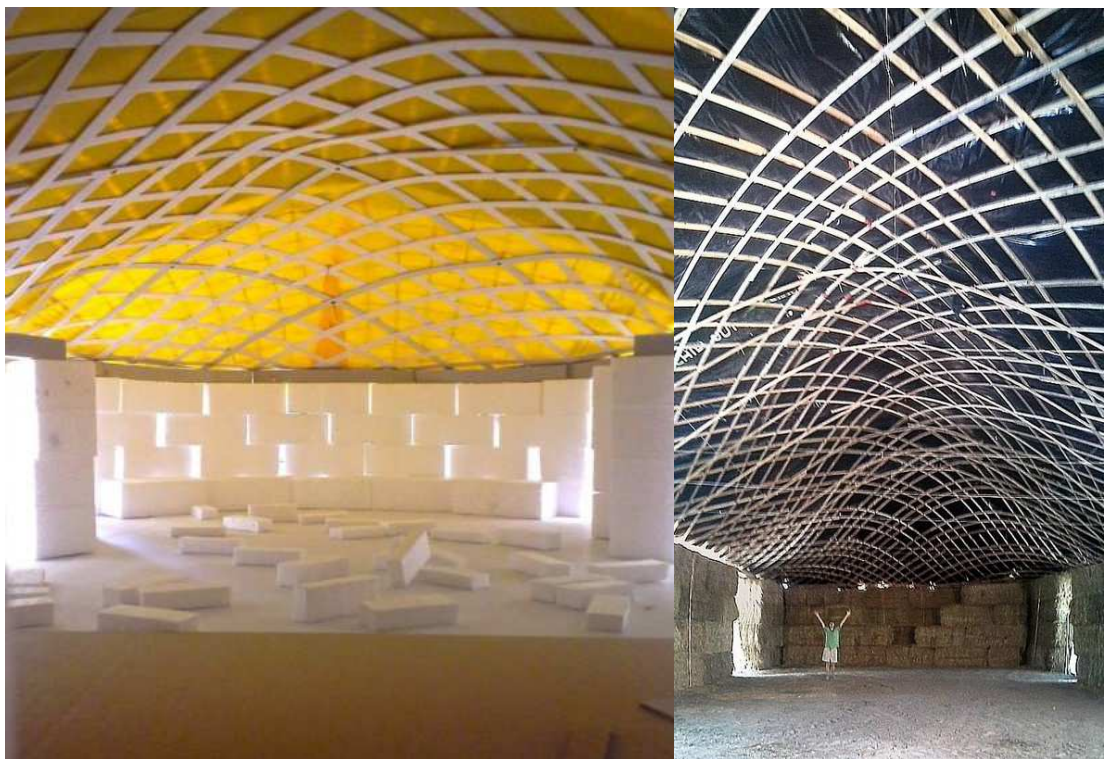

Figure 17: Physical model interior

Figure 18 - Photo of reality

\section{Multi-purpose pavilion in Trebesov}

The newest project (finished 8/2016), which includes all previously reached knowledge and experiences came into being as the first complete made long-term structure in cooperation with the Matrix company and specialized architect and statical engineer from Austria, Matrix is supporting young creative and specialized on larch and oak wood.

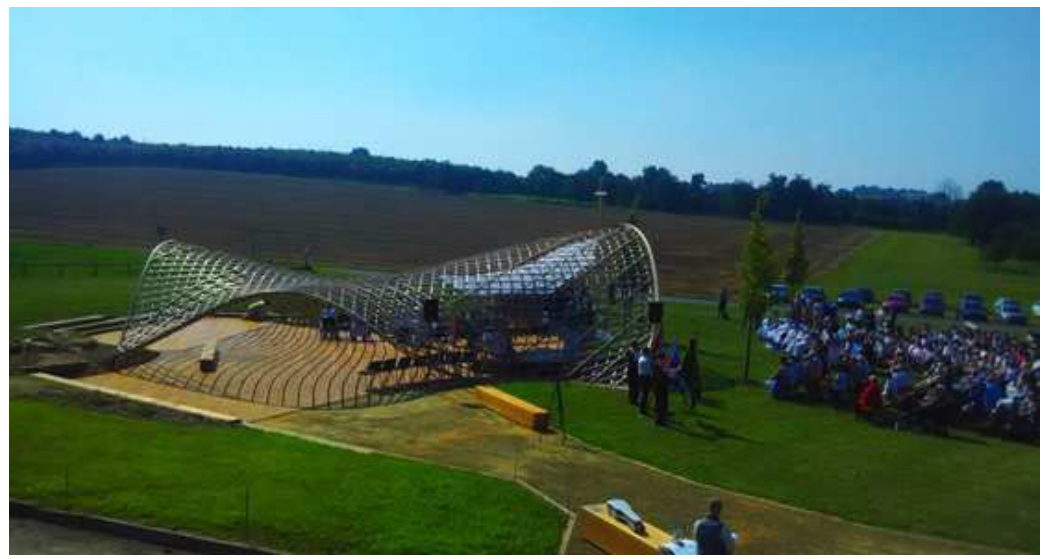

Figure 19: Matrix pavilion - Harvest Mass

This pavilion came into existence as a serious project, reflecting larch timber quality and the company philosophy. The whole structure is made of typical roof laths of dimension $30 \times 50 \times 5000 \mathrm{~mm}$, anchored by 22 pcs of $2 \mathrm{~m}$ long ground anchors. In general, among other things, there were used $1700 \mathrm{~m}$ larch timber laths, $550 \mathrm{~m}$ rope, 2200 screws for main joints, same amount of nuts, 4400 washers, 1500 fulltwists (all stainless steel). Total area of wooden terrace $210 \mathrm{~m}^{2}$, membrane $42 \mathrm{~m}^{2}$ (Ferrari Soltis W96). 
The whole project (since first sketches and physical models were made to the final look) took exactly one year.

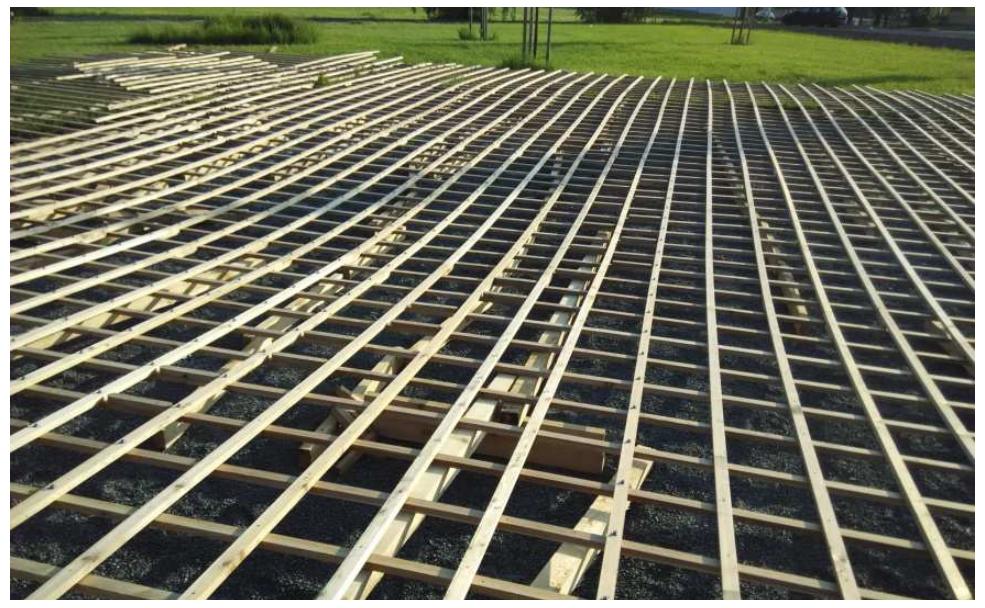

Figure 20: Grid in flat position

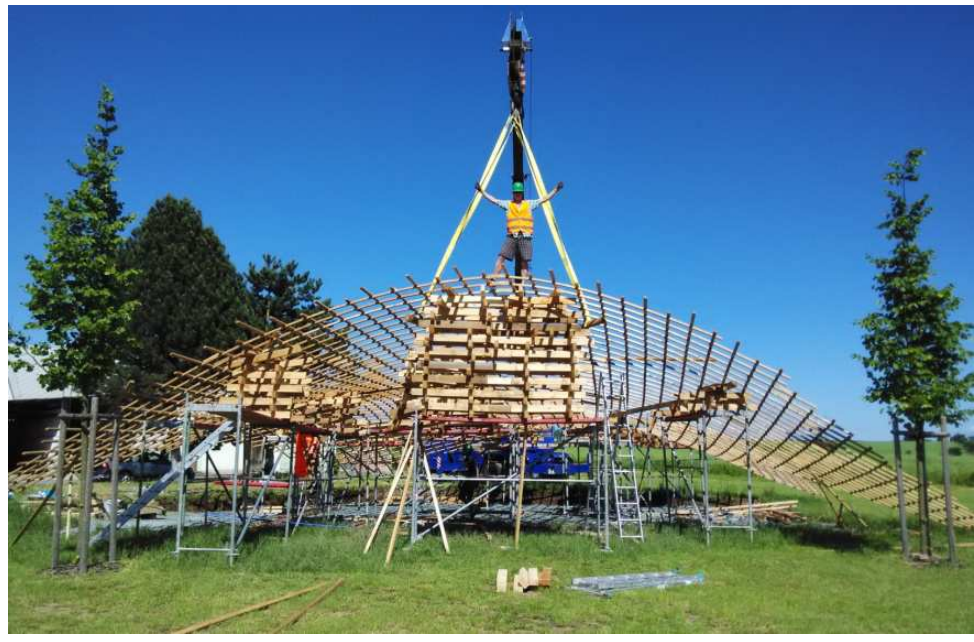

Figure 21: Erection procedure

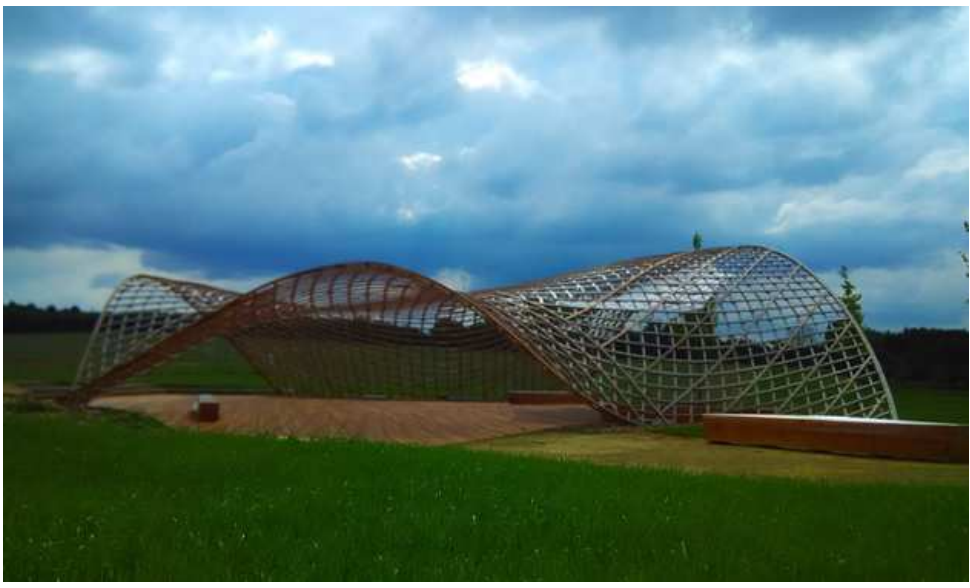

Figure 22: Matrix pavilion - photo of reality 


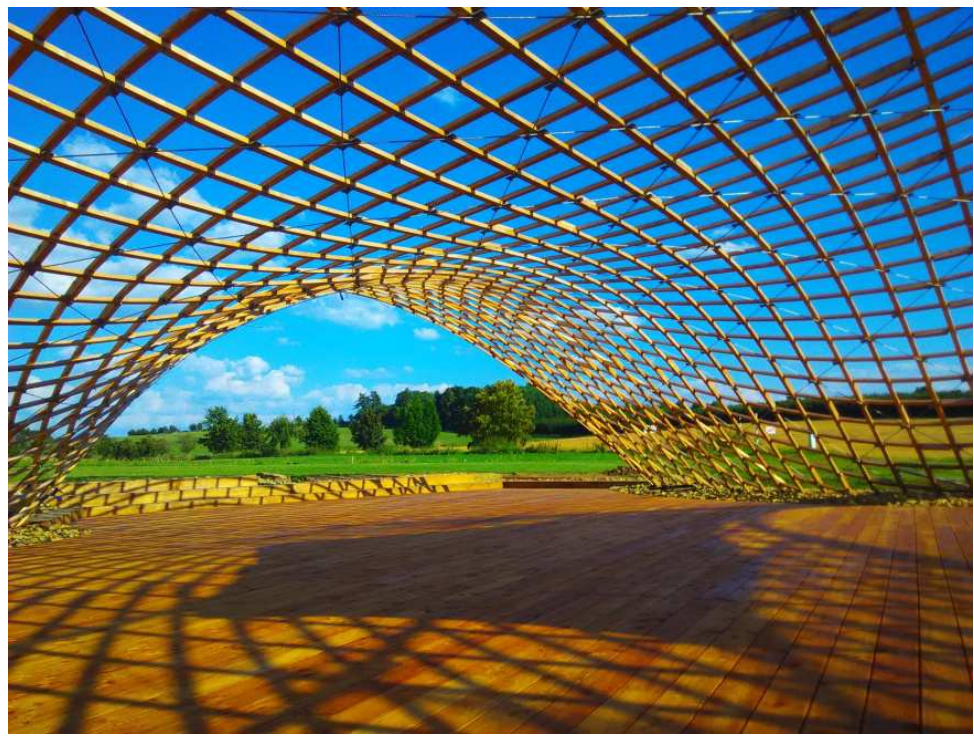

Figure 23: Interior view

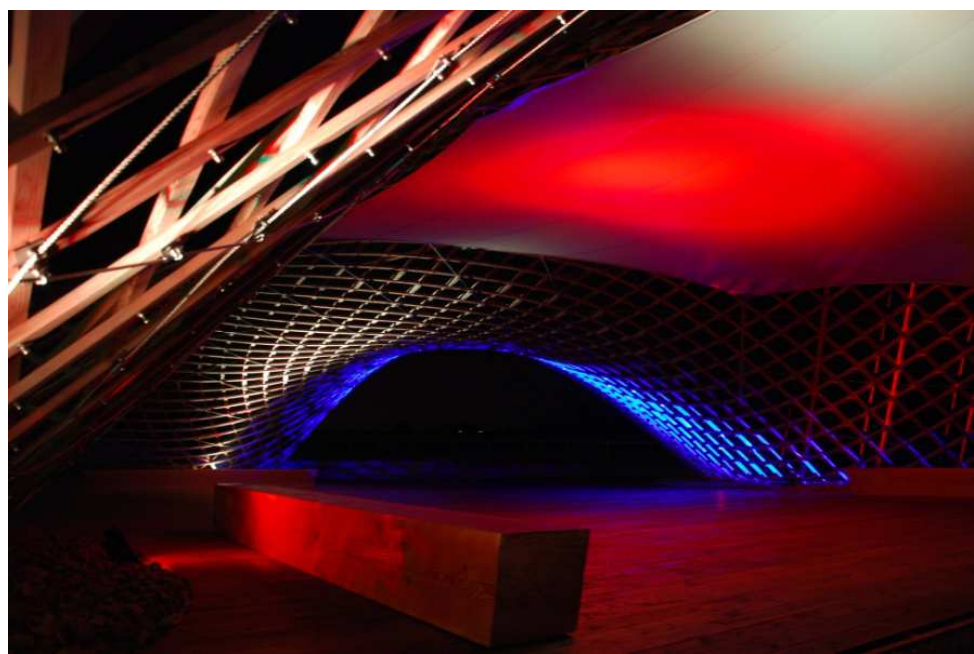

Figure 24: Matrix pavilion at night

\section{Conclusion}

The goal of the research was to create a feasible design of a grid shell structure and to build up a structure while understand the issues of building this more than interesting project itself. As a starting point there was a first workshop organized in cooperation with students and friends. Many different materials were used for the physical modeling and the very first grid was assembled. This workshop became very valuable source for answering many questions, where must be highlighted few to gain the idea of its virtue how to erect. Above all, when a grid is bended even in one curvature it wants to straighten to the starting flat position. 
In the specific case of first small structure there must have been the anchoring done forcibly by using $4 \mathrm{~mm}$ wires. The shape must be designed precisely and in case of generally larger meshes. They are easier to bend in double curvature because of the bending limits due to cross-section capacity. In case of timber it means that as small structure we want to build, as thin cross-section we should use. This phenomenon causes some difficulties within connections of these elements. The whole research was since the beginning based on the cooperation between many people - architects, engineers, specialized companies, professional craftsmen and enthusiastic friends.

\section{References}

[1] Shell Structures for Architecture - Sigrid Adriaenssens, Philippe Block, Diederik Veenendaal, Chris Williams, London 2014

[2] IL10 Grid shells, University Stuttgart 1974, page 21, 22, 26, 140, 141

[3] Schalen - Ekkehard Ramm, Eberhard Schunck, Heinz Isler, 1986, page 69

[4] https://en.wikipedia.org/wiki/Yurt (retrieved on 11.6.2015)

[5] https://quadralectics.wordpress.com/4-representation (retrieved on 21.6.2015)

[6] www.tentwood.cz/cs/konstrukce-jurt-komplet (retrieved on 15.6.2015)

[7] Shell Structures for Architecture - Sigrid Adriaenssens, Philippe Block, Diederik Veenendaal, Chris Williams, London 2014, page 8

[8] A Design Tool for Timber Gridshells - M.H. Toussaint, Delft University of Technology, 2007, page 72,73 
